\title{
La physis del mundo en la concepción barroca de Baltasar Gracián*
}

\section{The physis of the world in the baroque conception of Baltasar Gracián}

\author{
Luis Sáez Rueda \\ https://orcid.org/0000-0003-1490-3334 \\ Universidad de Granada \\ ESPAÑA \\ Isaez@ugr.es
}

[Hipogrifo, (issn: 2328-1308), 9.2, 2021, pp. 981-997]

Recibido: 19-05-2021 / Aceptado: 12-07-2021

DOI: http://dx.doi.org/10.13035/H.2021.09.02.66

Resumen. El artículo intenta mostrar, tomando como referencia la obra de Baltasar Gracián, que la experiencia barroca del Deus absconditus conduce a presuponer una physis inherente al mundo. Frente a la tesis de una oposición excluyente entre el todo infinito trascendente y la nada del mundo, el autor defiende la relación incluyente entre ambas en la forma de una presencia despresente, o ausencia presente, de lo divino en el mundo, aporética que se muestra generadora de la profundidad de lo finito. La presencia del Artífice en tal esfera permite afirmar tanto una physis de lo natural como una physis del mundo cultural, relacionadas por el ingenio. La simultánea despresencia de lo divino como totalidad implica una physis del mundo finito en su más amplio sentido, en la que se reúnen las dos anteriores. Se trata de una physis paradójica de lo creado, matriz autopoiética que abre en lo finito una peculiar infinitud infinitamente infinita.

Palabras clave. Barroco; Gracián; naturaleza; cultura; physis; todo-nada; infinito.

Abstract. This article tries to show, taking the work of Baltasar Gracián as a reference, that the baroque experience of Deus absconditus leads one to presuppose a physis inherent in the world. Faced with the thesis of an exclusive opposition

* Este trabajo ha sido realizado en el marco del Proyecto de Investigación Herencia y actualización del Barroco como ethos inclusivo (PID2019-108248GB-I00 / AEI / 10.13039/501100011033), financiado por el Ministerio de Ciencia e Innovación del Gobierno de España. 
between the transcendent infinite whole and the nothingness of the world, I defend the inclusive relationship between the two in the form of a non-present presence, or present absence, of the divine in the world, an aporia that is shown to generate the depth of the finite. The presence of the Artificer in this sphere makes it possible to affirm both a physis of the natural and a physis of the cultural world, related by wit. The simultaneous lack of presence of the divine as a totality implies a physis of the finite world in its broadest sense, in which the two aforementioned physis come together. It is a paradoxical physis of what is created, an autopoietic matrix that opens up a peculiar infinitely infinite infinite in the finite.

Keywords. Baroque; Gracián; Nature; Culture; Physis; All-nothing; Infinite.

Es sabido que el Barroco se desarrolla en el seno de la crisis que la modernidad atraviesa en el siglo XVII, una de cuyas claves reside en el enfrentamiento entre la naturalización científica del mundo y la comprensión religioso-metafísica de la época pre-moderna. Mientras esta última entendía lo real como un cosmos orgánico, centrado y cerrado, la primera lo secularizaba, lo abría hacia su infinitización y lo sometía a explicación legaliforme. El alma barroca experimenta esta oposición y la trasciende creativamente. Como nos gustaría mostrar -a través del pensamiento de Gracián-, lo divino trascendente es experimentado como absconditus e injertado en la forma de una ausencia operante en el mundo, proceso a través del cual no solo la naturaleza en sentido estricto, sino la naturaleza del mundo finito en su totalidad, adquiere una profundidad cualitativa no reductible a leyes, una profundidad que - pensamos - recupera la noción de physis de un modo muy original.

\section{EL SENTIDO DE LA PHYSIS}

La Grecia clásica, en especial la filosofía presocrática, utilizó el término physis para referirse a la naturaleza en cuanto autogeneración creativa (autopoiesis). Es el dinamismo por el cual lo existente de un modo concreto $-y$, por tanto, en su multiplicidad y diferencia - llega a ser a partir de lo indefinido e ilimitado (ápeiron) ${ }^{1}$. La realidad concreta no puede estar fundada - como concluyó Anaximandro- en un principio también concreto (arjé), dado que habría que preguntar ad infinitum por el arjé del arjé. La potencia natural de fondo, pues, es pensada como una ausencia de limitación que se determina a sí misma o individúa en la rica variedad de los entes precisos. La physis se expresa en la naturaleza observable y ordenada, pero no es reductible a una reglamentación legaliforme; es potencia (o intensio, en el mundo latino). Trátase, en lenguaje medieval, de la natura naturans, emergente e irreglable, que se corporeiza en la natura naturata reglada.

El siglo XVII es una de las épocas en las que esta concepción es reavivada. Spinoza concibe la entera realidad, Dios, como potencia, natura naturans infinita e inmanente a sus infinitos atributos ${ }^{2}$. Leibniz, cuya concepción del mundo es plena-

1. Calvo Martínez, 2000, pp. 26 y 33-36.

2. Spinoza, Ética, I, proposición XXXIV. 
mente barroca, sustituye el monismo spinoziano por un pluralismo de mónadas, cada una de las cuales es materia y alma. La materia está conformada internamente por la dimensión intensiva de la fuerza (vis)3. Y la fuerza es, al mismo tiempo, el fondo continuo e infinito de la realidad, actuando como un «vínculo sustancial» entre la pluralidad y diferencia de las mónadas ${ }^{4}$. No es difícil ver en este vínculo entre fondo infinito de potencia y realidades monádicas concretas una versión de la relación fundamental de la physis, una versión que, según Deleuze, constituye ese rasgo barroco central al que llama «pliegue», la función operatoria que comprende el todo como una unidad plástica e infinita respecto a la cual las realidades concretas serían individuaciones en la forma de «invaginaciones» ${ }^{5}$. En Leibniz se trata de un mundo profundo y proteico conformado por fuerzas; y si este se hace compatible con el «principio de razón suficiente» - que implica la necesidad en todo lo que sucede- es porque presupone que Dios crea el mejor de los mundos posibles y establece una «armonía preestablecida» entre todas las mónadas, entre las que existe una unidad de «interexpresión» en la medida en que todas expresan en armonía una misma totalidad 6 .

El Barroco se opone, así, a la modernidad cartesiana. Considerando a la noción de «fuerza» o «potencia» como oscura, piensa Descartes que es reductible a la dimensión puramente cuantitativa del efecto geométricamente expresable: todos los fenómenos estarían vinculados entre sí por una relación de magnitudes, es decir, por una función?. Surge de aquí el modelo de saber moderno fundado en la Mathesis Universalis, ciencia del «orden y la medida», a la que remitiría todo tipo de conocimiento del mundo ${ }^{8}$. Como se verá, en Baltasar Gracián la ontología barroca de la potencia, que difiere de la cartesiana y cientificista, está también presente, con matizaciones específicas.

\section{CONTRA LA OPOSICIÓN EXCLUYENTE «TODO TRANSMUNDANO - NADA MUNDANA»}

El camino que conduce, en Gracián, a la inserción de esta physis en el mundo comienza con la experiencia de una aporía. Por un lado, la espesura de lo múltiple y diverso se abre paso en la crisis del cosmos premoderno. Así, Gracián ensalza esta condición de lo creado, «centro de hermosas variedades [...], diferentes todas en propiedades y en esencias» ${ }^{9}$. Ahora bien, la unidad orgánica y total de tal diversidad y diferencia es, por otro lado, sustraída del mundo, fenómeno al que conducen las circunstancias socioculturales y una comprensión de lo divino como absconditus.

3. Leibniz, Monadología, parágrafo 11

4. Leibniz, Die Philosophischen Schriften, II, pp. 517-518.

5. Deleuze, 1989, p. 17.

6. Deleuze, 1989, p. 107.

7. Ver Descartes, Principes de la Philosophie, II, parágrafos 4, 11, 23, 41.

8. Descartes, Reglas para la dirección del espíritu, IV y V.

9. Gracián, El Criticón, I, crisi 3, p. 826. 
En primer lugar, el siglo se experimenta atravesado por procesos ciegos e ingobernables -como el del capital y el de la política realista, pragmática e instrumental ${ }^{10}$ - que tienden a imponer una equivalencia de todas las cosas, así como por el impulso, igualmente allanador, de la razón analítica y matematizante. Los hombres son empujados a la uniformización, convirtiéndose en «orates igualados» "17; a los elementos de la naturaleza el espíritu de cálculo les sustrae su «diferente propiedad», sometiéndolos a una disposición «afectada y uniforme»12; en general, avanza una comprensión del mundo asequible al frío entendimiento, que genera «homogéneos sus conceptos», faltándole la excelencia del arte "y con ella la variedad, gran madre de la belleza» ${ }^{13}$. Es así expulsada hacia el ámbito de la trascendencia la verdadera totalidad, la orgánica, es decir, el todo como «concierto [...] de tan varia multitud» ${ }^{14}$. La Mentira, en consecuencia, firma el «destierro» de la Verdad ${ }^{15}$. Y este vaciamiento hace del mundo un teatro de apariencias y engaño, lo convierte en «un cero», todo «aire y vanidad» 16 .

A esta huida del todo hacia el ámbito trans-mundano se une, en segundo lugar, la experiencia religiosa de un deus absconditus. Dios, el todo-fundamento del mundo, es aprehendido, al unísono, como «un infinito en todo género de perfección» que, aunque se manifiesta en su creación, se mantiene encubierto, «como soberano Príncipe, estando retirado a su inaccesible incomprehensibilidad» ${ }^{17}$. El héroe barroco aparece, así, como un ser viator que aspira a lo eterno, partiendo de la nada y ascendiendo al todo ${ }^{18} \mathrm{e}$ imitando, en ese vuelo, a su creador, es decir, manteniendo su fondo inaccesible, protegiendo la «incomprehensibilidad» de su «caudal» 19 .

En esta crucial relación entre todo-infinito y mundo se cifra, tal vez, la mayor ambigüedad del barroco hispano. ¿Es la retirada del todo divino e infinito una completa nadificación del mundo? Una de las interpretaciones más consolidadas al respecto responde afirmativamente. Según esta perspectiva, el todo y la nada operan en el barroco hispano como opuestos excluyentes. Ningún ámbito toca al otro, de manera que la imposibilidad de aprehender a dios en el mundo coincide con la imposibilidad de aprehender realidad en un mundo sin Dios, estado de ruptura que representaría un «algoritmo del barroco» ${ }^{20}$. Emerge la experiencia de que la irrealidad del mundo es su última verdad. Una perspectiva como esta, por ello, está asociada con una tesis ficcionalista, según la cual el Barroco hispano expul-

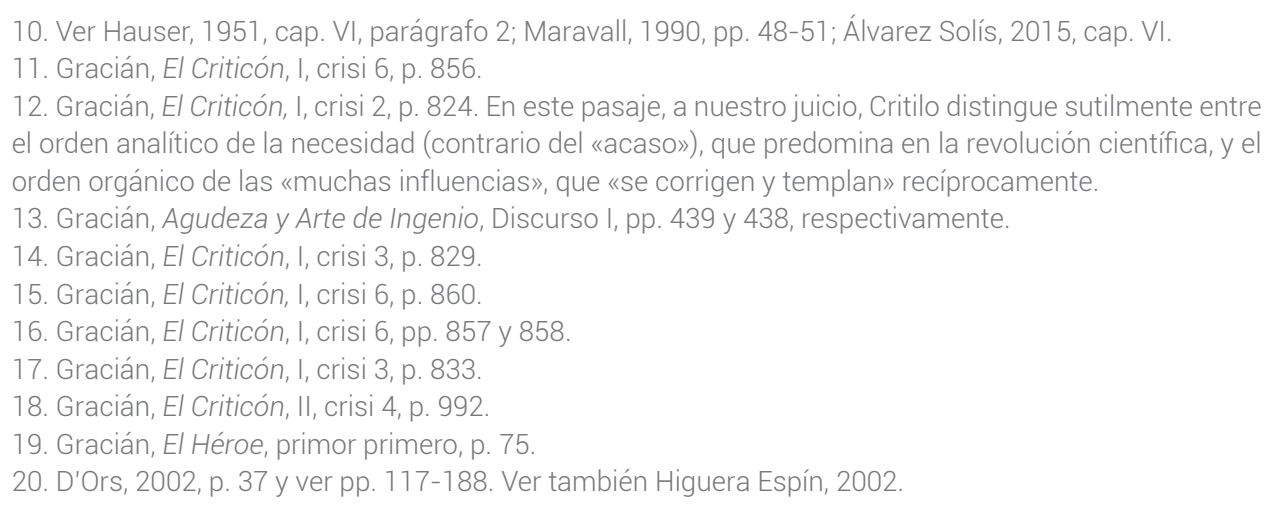


sa la sustancialidad del mundo ${ }^{21}$. Esta tesis es, sin embargo, compatible con el reconocimiento de que el alma barroca resiste al vaciamiento del mundo. Pero, si hubiera que pensar tal resistencia desde estas premisas, habría que asociarla a su capacidad eminentemente constructiva, es decir, a su poder creativo para construir o producir artificiosamente una profundidad del mundo, al sobrecodificarlo a través de lo que Eugenio Trías llamó «escenificación teatral del Infinito»22.

Contra esta tendencia interpretativa, nos parece que el imaginario barroco no es meramente una «construcción» representacional. Es cierto que la escenificación del infinito genera, a través de la alegoría, un espacio analógico de relaciones entre las realidades cuya trama está recorrida por lo invisible, dando lugar a una illusio colectiva o fantasmagoría compartida ${ }^{23}$. Ahora bien, lo que es así construido es, al mismo tiempo, reconstruido como profundidad real del mundo. Si el mundo fuese completo vaciamiento, la resistencia moral del ser humano al engaño apariencial no podría ser pensada - a nuestro juicio - más que como adhesión incondicional a un dogma teológico de fe y no como efectivamente arraigada en una propensión esencial suya. Y esta subsistencia inmanente de la esencia respecto a la apariencia es afirmada por Gracián en diversos lugares ${ }^{24}$. Profundizaremos en lo que sigue esta tesis, ligando la esencia a la physis, primero refiriéndola al ser humano y después descubriéndola en el mundo.

\section{LA PHYSIS HUMANA COMO PROCESO DE INDIVIDUACIÓN}

«Tanto se requiere en las cosas la circunstancia - dice Gracián- como la substancia; [...] por la corteza del trato sacamos el fruto del caudal» ${ }^{25}$. El caudal, esta sustancia del ser humano, no posee un carácter parmenídeo ni se corresponde con la esencia en un sentido aristotélico, opuesta a los accidentes. En sintonía con la ontología de la potencia que prolifera en la época, es concebido como una dimensión de fuerza, energeia o vis activa; es un acontecimiento dinámico e intensivo que se expresa o encarna en el modo de operar, en las acciones y formas de afrontar el mundo, es decir, en las maneras ${ }^{26}$. Quiere esto decir que el ser humano posee una medida interna de su puesta en escena en el teatro del mundo: el ajuste a su caudal, en virtud del cual la constelación de artificios en que se desenvuelve su acción no se identifica meramente con el engaño apariencial, sino que adquiere un carácter auto-realizativo y auto-expresivo en un noble sentido. El puro parecer estratégico adquiere el carácter de una desviación o perversión de la naturaleza

21. Hay posiciones que le atribuyen un nominalismo escéptico sin sustancia (Blüher, 1969, pp. 530-531). Otros atribuyen al Barroco hispano una filosofía artificial que recupera a los sofistas (Rosset, 1974, pp. 199 y ss.; Borghi, 1991, pp. 55 y ss.). Jankélévitch llega a mantener que el Barroco hispano se desinteresa del ser para magnificar el aparentar, lo que expresaría -afirma - un vacío narcisista (1992, pp. 76 y 87)

22. Ver Trías, 1996, pp. 161 y ss.

23. Rodríguez de la Flor, 2012, pp. 44-61.

24. El nexo entre el aparecer y la norma interna de la esencia o de la «entereza» aparece en Oráculo Manual, 14, 97, 103, 106, 175, 219, 277, 289.

25. Gracián, El Discreto, XXII, p. 329.

26. Ver Cerezo Galán, 2015, pp. 39-46; Ayala, 1987, pp. 151 y ss. 
activa humana. Tal perversión es condición de posibilidad de la insistente caracterización graciana del teatro apariencial como un estado de inversión de valores, en virtud de la cual lo más bajo e inmoral es tomado por lo mejor, mientras lo que concuerda con la recta expresión del caudal se identifica con lo peor ${ }^{27}$. La acción no está marcada, en consecuencia, por la nada de la pura voluta, sino que hunde sus raíces en una naturaleza dinámica de lo humano en cuanto caudal, el cual se materializa en modos de operar a través de los cuales el héroe barroco se hace a sí mismo proteicamente ${ }^{28}$.

Tal hacerse resistiendo al engaño del mundo y ateniéndose a la intensificación del caudal -esto es lo crucial- tiende a elevarse a lo eterno trascendente «con ambiciones de infinito» 29 justo en la misma medida en que profundiza en el propio infinito interior. Ascender a lo infinito transmundano es paralelo a un descenso en el hondón infinito de sí. El caudal, en efecto, carece de una forma limitada y predeterminada; es informe, pues al hombre «hízolo el cielo indefinido» ${ }^{30}$, de modo que él mismo es un misterio para sí, un laberinto inabarcable cuyo fondo se retira, a imagen del propio Dios absconditus ${ }^{31}$. Llegar a ser persona persiguiendo lo eterno implica para Gracián un proceso de perfeccionamiento que involucra auto-conocimiento $^{32}$, un auto-desciframiento que, por laberíntico, es inacabable ${ }^{33}$. Y estas consideraciones apoyan -nos parece- la idea de que la naturaleza del hombre adquiere el ser, gracianamente pensado, de una physis. Posee una naturaleza generativa, naturans; su ser no está dado como un factum, sino que coincide con la potencialidad, por lo que es caracterizado como «compendio de todo lo natural»34. lo humano es ese fondo 35 indefinido (ápeiron) de potencia que adopta forma de modos variados y diferentes en cada praxis concreta. Esta physis inmanente al ser humano es congruente con su deseo de elevación viator hacia el cielo porque ella

27. Ver, por ejemplo, Gracián, El Criticón, I, crisi 6, p. 863. En este sentido, no podemos estar de acuerdo con las interpretaciones que describen la individualidad pensada por Gracián como trasunto del sujeto estratégico del mundo moderno y contemporáneo, próximo «a toda una estirpe de actores políticos oportunistas de todos los tiempos, a numerosos operadores e ideólogos de la moderna razón política instrumental, a muchos representantes y escenógrafos políticos de la sociedad del espectáculo» (González de Requena Farré, 2019, p. 125).

28. Gracián, El Discreto, Realce VII, p. 293. Gracián distingue a Proteo como el modelo al que aspira el hombre, que ha de expresarse en una multiplicidad de modos para ser cabal.

29. Gracián, El Discreto, VII, p. 292.

30. Gracián, El Discreto, VII, p. 293.

31. Gracián, Oráculo Manual, 3, p. 345: «Llevar sus cosas con suspensión. [...] Imítese, pues, el proceder divino». Este fondo absconditus del ser humano no es meramente estratégico y construido, sino ontológico. Ver Egido, 1996, cap. 2.

32. Ver Gracián, Oráculo Manual, 6, p. 346. Este autoconocimiento involucra, además, un «cuidado de sí» que presupone la búsqueda de una verdad ontológica, una verdad no reductible a la que es construida por los procesos del poder y la cultura, razón por la cual esta concepción barroca ofrece soluciones a los más actuales desarrollos, de origen foucaultiano, de la idea de «subjetivación» (ver Barroso Fernández, 2000). 33. Ver Egido, 2001, p. 173; Cerezo Galán, 2015, pp. 41-46 y 274; Rodríguez de la Flor, 2005, pp. 24-37 у $130-133$.

34. Gracián, El Discreto, VII, p. 292.

35. Caudal y fondo indefinido e insondable poseen un nexo interno. «Un corazón de un mar» y «gran ser, gran fondo y gran capacidad» es la madurez del hombre (El Discreto, III, p. 283). 
misma es su espejo, un infinito hacia dentro que es auto-creador, arte de sí en el sentido de la autopoiesis. Desde este punto de vista, entonces, el Criticón puede ser leído en la forma tanto de un ascenso hacia una alteridad transmundana, como de la narración de un auténtico proceso de individuación desde la profundidad de la existencia mundanal, es decir, como una génesis de sí, partiendo del caudaloso fondo indeterminado y cuestionante para ir determinándose como persona en su singularidad, lo cual acontece al tiempo que lucha contra un mundo que procede contra la virtud. En ese curso de la «milicia a la malicia»36, en efecto, debe el ser humano penetrar en sí mismo y resolverse en concreción, pues «no puede uno ser señor de sí, si primero no se comprehende [...] Conozca las fuerzas de su cordura y sutileza para el emprender [...]; tenga medido su fondo y pesado su caudal para todo» ${ }^{37}$. Ha de dar medida y peso, sí, a su caudal, es decir, configurar su informe potencia en modos de actuar prudentemente y de acuerdo con la ocasión. Procede, así - como ha descrito Simondon ${ }^{38}$ en referencia a la individuación humana- dando concreción a su individuación genérica por medio de una individualización y personalización singular. Si el ascenso viator, pues, despeja la universalidad de lo humano en su vínculo con lo eterno trascendente, la génesis individuadora desde lo insondable inmanente opera una singularización. Ambos cauces convergen -a nuestro juicio- en el camino por el cual lo humano aspira -utilizando el lenguaje hegeliano- a su universalidad concreta, si bien en la imposibilidad de una síntesis terrenal, pues «lo que ha de durar una eternidad ha de tardar otra en hacerse» 39 .

\section{PHYSIS NATURAL Y PHYSIS DEL MUNDO CULTURAL}

Más allá de lo que concierne al ser humano, la physis subtiende al mundo en su totalidad en la visión graciana. Frente a la hipótesis oposicional y excluyente que hemos analizado anteriormente, hay razones para sostener que el mundo es todo y nada simultáneamente. Esta aporía es precisamente lo que inserta un carácter trágico en el alma barroca ${ }^{40}$. El mundo es todo, porque tiene su fundamento en lo divino, y nada, porque tal fundamento se ha sustraído. Y es que la cualidad de absconditus no coincide con la de otiosus, propia del deísmo. Como señala Gracián, lo enigmático de lo creado reside en que, en su espesor, el creador es «escondido y manifiesto, tan lejos y tan cerca» ${ }^{41}$. Se trata de un Deus revelatus que, paradójicamente, se sustrae en el mismo acto de manifestación. Tal sustracción es una forma de presencia y de ausencia concurrentes muy peculiar.

36. Gracián, El Criticón, II, crisi 9, p. 1050.

37. Gracián, Oráculo manual y Arte de prudencia, 89, p. 370

38. Simondon, 2009, pp. 395-405. El proceso de individuación que suponemos en El Criticón parte, como en Simondon, de una naturaleza como physis, cuyo fondo no es legaliforme o mecánico. Distinta motivación - de carácter racionalista - tiene el principio en Leibniz. Las ecuaciones mecánicas requieren, según el autor alemán, un principio de individuación que unifique lo universal y lo singular: el axioma metafísico de la equipolencia entre la causa plena y el efecto íntegro (Orio de Miguel, 2017, pp. 86-88).

39. Gracián, Oráculo manual y Arte de prudencia, 57, pp. 360-361.

40. Ver Goldmann, 1955, especialmente parte I, y Echeverría, 2006, pp. 183-193.

41. Gracián, El Criticón, l, crisi 3, p. 833. 
Pospongamos, por el momento, el carácter de ausencia de lo divino. Como presencia, lo divino forja el carácter auto-generador de lo real. Que Gracián se refiera a Dios como el «supremo Artífice» ${ }^{42}$ implica que es concebido como el principio artístico del mundo, el cual aparece, entonces, como potencia auto-creativa. El artificio, que caracteriza al mundo, no puede ser tomado solo como apariencia hueca y artificiosidad engañosa. Y es que el consabido principio del barroco hispano según el cual en el mundo todo es artificio esconde una ambigüedad. «Artificio», según la definición ofrecida por Covarrubias ${ }^{43}$, es «la compostura de alguna cosa o fingimiento». La segunda significación remite al puro parecer engañoso, pero la primera está vinculada al aparecer desde sí en una con-posición de manifestaciones ensambladas, es decir, al comparecer de lo real como poder creativo que se da forma o modela a sí mismo: como autopoiético ${ }^{44}$. Se trataría, en la naturaleza, de un poder naturante. Ahora bien, en un sentido estricto, el artificio es atribuido por Gracián al mundo humano de la cultura, con la acepción específica del arte como potencia imaginativa y simbólica. En cualquier caso, ambos extremos expresan una misma creatividad que desborda el ámbito de la pura ley mecánica, apareciendo la humana como una prolongación y ampliación de la natural. Este es el sentido metafórico de la dedicatoria de El Héroe, según la cual, si la naturaleza produce «prodigios», el arte hace «milagros» ${ }^{45}$. Entre naturaleza y cultura no hay, pues, una ruptura radical, sino una continuidad en el orden del poder creativo. «Es el arte - sentencia Gracián-complemento de la naturaleza y un otro segundo ser que por extremo la hermosea y aun pretende excederla en sus obras» ${ }^{46}$.

Una primera profundización de esta línea de reflexión nos viene propiciada por la noción de ingenio, la más excelsa forma de inteligencia, según Gracián, y facultad que se pone en obra en el arte. El ingenium, que para los latinos era sinónimo de naturaleza y el equivalente de la physis griega, forma parte ya -como argumenta Hidalgo Serna- de la naturaleza misma; en caso contrario «resultaría una potencia arbitraria y adulterada» ${ }^{47}$. Esta circunstancia refuerza la idea de una continuidad entre naturaleza y cultura. Si en Aristóteles el arte es vicario de la naturaleza, porque actúa imitándola (Física, B2), en Gracián habría que decir que la obra del ingenio, el arte, «en cuanto poder "naturante", conecta con el propio acto creador de la naturaleza» y la incrementa mediante un nuevo "orden autoteleológico» ${ }^{48}$.

En breve veremos que el binomio naturaleza-cultura demanda ser trascendido. Manteniéndonos aun en este binomio obtenemos, ciertamente, resultados interesantes en cuanto a la noción de una physis del mundo. Gracián pone en claro que la naturaleza, creada directamente por Dios, es perfecta y no admite mejora, mientras que todo lo que han añadido los hombres es imperfecto, llegando, incluso, a adop-

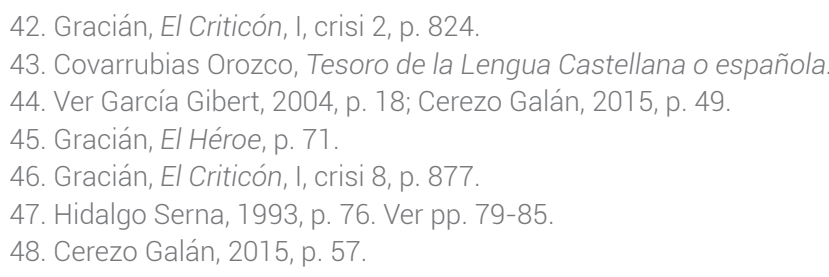


tar un aspecto espantoso ${ }^{49}$. En un sentido, pues, el ingenio complementa y excede a las obras de la naturaleza, generando -en cuanto sobrenaturaleza- un ámbito reflexivo y simbólico que falta en aquella. En otro sentido, sin embargo, el ingenio puede devaluar la obra de la naturaleza, al convertir el artificio (que, como hemos visto, es ya inherente al ámbito natural) en un espacio de fingimiento, engaño y espíritu estratégico. Habría que preguntar, en este punto, por el tipo de naturaleza que es, así, devaluada. Se deduce, de inmediato, que no se trata de la naturaleza en cuanto tal, sino de la naturaleza del mundo en el sentido estricto de «mundo humano». El ingenio, como creador de cultura, es - como señala Aurora Egido- un poder gestante, generativo, que se actualiza en concreciones del arte. Este himeneo entre ingenio y $\operatorname{arte}^{50}$ da lugar también a ideofactos, es decir, a modos de conducta y estratagemas de actuación ${ }^{51}$. Junto a ello, el «raciocinar, discurrir y entender» permiten una ordenación hacia «Dios, conociéndole, amándole y sirviéndole» ${ }^{2}$. Con la expresión physis cultural del mundo nos referimos a esta autogestante esfera mundanal de lo humano como dimensión de génesis naturante: parte del ingenio como ápeiron, es decir, como fondo informe e indeterminado de potencia, y se concreta, a través del arte, en una comprensión de lo real y en una praxis social. Esta potencia del ingenio humano está entreverada con un impulso de infinitud o de ascenso a lo eterno - propia del homo viator-, por lo que posee una normatividad interna coincidente con la tensión hacia lo infinito. Lo que en el engaño puramente apariencial es devaluado es esta physis y su normatividad. Y como el engaño y la reducción del mundo a un teatro huero e interesado son obra del poder mismo que se pone en juego en lo humano, podríamos decir - a nuestro entender- que en los renglones torcidos de la vida humana la physis cultural del mundo se depotencia a sí misma, contradiciéndose, merced a la libertad que la acompaña. De ahí que la perversión del mundo termine, para Gracián, en un autófago «mundo inmundo» ${ }^{53}$.

\section{LA PHYSIS DEL MUNDO CREADO Y FINITO EN SU TOTALIDAD}

Es preciso distinguir, pues, entre la naturaleza de la naturaleza y la naturaleza del mundo ${ }^{54}$. La continuidad entre ellas se intrinca con una discontinuidad. La primera es también una physis, pues es ya ingeniosa y, como hemos visto, recibe del Artífice su textura de artificio, en el sentido elevado según el cual crea su propia «compostura». La distinción crucial con la segunda radica, fundamentalmente, en que es perfecta, lo cual -pensamos- significa que opera a través de un autoordenamiento no susceptible de volverse contra sí mismo y depotenciarse, como

49. Ver Gracián, El Criticón, I, crisi 5, pp. 844-845,

50. Ver Egido, 2014, pp. 21-49.

51. Ayala, 2004, p. 128

52. Gracián, El Criticón, I, crisi 3, p. 829

53. Gracián, El Criticón, I, 6, p. 863.

54. En este punto nuestra reflexión es convergente con la de Escribano Cabeza (2018, pp. 587-588), si bien no coincidimos en que el mundo siga la lógica de lo útil (p. 590). 
ocurre en el mundo55. La physis de la naturaleza, por este motivo, no puede ser pensada como un fondo subyacente a la physis del mundo. Su ordenación perfecta impide que podamos entenderla en la forma de un estrato genético profundo, pues de él no puede emerger un mundo imperfecto. La naturaleza no es originaria respecto al mundo en este sentido ontológico vertical, sino, más bien, en un respecto ontológico horizontal de precedencia diacrónica. Constituye el orden que es roto en el mundo humano. El ingenio humano, en este sentido, surge en y de la naturaleza, pero funda un ámbito que es disruptivo en la continuidad; media -como señala Cerezo Galán- entre naturaleza y mundo cultural y es frontera entre ambas ${ }^{56}$.

Este resultado es de importancia capital. Y es que, si se toma a esta naturaleza perfecta como el fondo universal y genético de todo lo real, el pensamiento graciano se aproximaría erróneamente a la concepción de Spinoza, en la que lo natural es la sustancia única y fundamental que se expresa en diferentes atributos y modos, con lo cual habríamos identificado a Dios con la physis natural en un inmanentismo completo. Frente a Spinoza, Gracián afirma un Artífice que no solo es anterior a la naturaleza y al mundo, sino que se sustrae en su propia manifestación en ambos. Tal es la especificidad del barroco hispano, contemplado desde la perspectiva graciana, la de caracterizar aporéticamente al ser que se pone en obra en todo lo existente. Pero esto implica que hay una physis del mundo en un sentido global, que incluye a la naturaleza y al mundo concreto humano y que se expresa en cada uno de ellos.

Si hasta ahora hemos seguido la estela de la presencia divina en el mundo, es necesario matizarla haciendo intervenir al otro elemento de la aporía «todo y nada» de la que hemos partido: la ausencia de Dios. La sustracción de lo divino reside en su carácter de totalidad. En el mundo humano se ausenta -como hemos señalado ya- la verdadera totalidad, el orden sintético en su completitud. Y esta huida de la verdad integral determina una pluralidad de perspectivas sin cierre, de modo que «hoy todo está en opinión y según como se toman las cosas» ${ }^{57}$. El retiro de

55. En este sentido estamos de acuerdo con Fernández Ramos (2010), para quien es en el mundo humano donde se ofrece una guerra y una inversión de valores y no -como en Hobbes - en un supuesto estado de naturaleza. Este contraste permite, además, marcar las distancias -en la línea de nuestra argumentación - entre la comprensión hispana del mundo humano y social y el mecanicismo racionalista. Mientras que la modernidad racionalista (como la representada por Hobbes) tiende a consagrar una comprensión del cuerpo social en la que prima la metáfora mecanicista, «estableciendo una equivalencia entre el cuerpo natural y el mecanismo artificial del autómata», la modernidad alternativa (y sofocada) que representa Gracián «entiende la sociedad como un cuerpo orgánico, vivo» (Fernández Ramos, 2017, p. 15). Tal auto-organización no se devalúa dejando de funcionar (como hace un mecanismo), sino -como hemos intentado mostrar en el seno de una teoría filosófica general de la «physis cultural» - volviéndose contra sí misma, depotenciándose (Sáez Rueda, 2015, parte primera).

56. Cerezo Galán, 2015, pp. 49-53.

57. Gracián, El Criticón, III, crisi 5, p. 1166. Hay que señalar que la necesidad de mantener en su «incomprehensibilidad» al propio caudal personal -que hemos señalado anteriormente- pone de manifiesto que el retiro de la Verdad y la ausencia de Dios se corresponden con el retraimiento del sabio, lo cual es subrayado por Gracián, por ejemplo, en El Criticón, I, crisi 6, donde explica que, en su tiempo, «Toda bestia y todo bruto han ocupado las ciudades. Ésas rúan las calles, pasean las plazas y los verdaderos hombres de bien no osan parecer, viviendo retirados dentro los límites de su moderación y recato». En 
la verdad total no conduce a la nulidad del mundo, sino a una finitización de la verdad en una multiplicidad inagotable de rostros a través de las conformaciones del arte en las que se concreta el ingenio, por lo que discurre «con artificio, usa de las invenciones» ${ }^{58}$. Hay una verdad intrincada en el artificio que es el mundo y en su trama infinita, una «verdad del mundo aparencial», como ha señalado García Gibert ${ }^{59}$, generada polívocamente por el ingenio, razón por la cual este es calificado como «finitamente infinito» ${ }^{60}$. En la naturaleza, por su parte, el dios presente también está ausente, y no solo en el sentido epistemológico de su exceso respecto a las capacidades comprensivas del ser humano, sino más profundamente, en el sentido plenamente ontológico de su detracción en la misma comparecencia natural, pues -como ya habíamos aludido - está retirado en su incomprehensibilidad; el retiro de lo divino como todo es condición de la presencia de lo múltiple, «él [Dios] hace que se vean todas las cosas y no permite ser visto» ${ }^{61}$.

La naturaleza y el mundo humano participan de esta textura aporética del mundo ${ }^{62}$ en su acepción global, en cuanto simultaneidad de presencia y ausencia de lo divino. En este sentido, «mundo» no se opone a «naturaleza», sino a Dios. Se trata del mundo integral que se expresa en lo natural y en lo cultural y que es «un compuesto de todo lo criado» 63 . Pues bien, este mundo omniabarcante es -a nuestro juicio- una physis más básica, subyacente. En cuanto global, podemos Ilamarla physis del mundo finito. Lo esencial de su textura reside en que no es solo una potencia generadora, sino, al mismo tiempo, una falta de plenitud que no es incompatible con la perfección de la naturaleza, pues esta «falta» es, ella misma, fuente de una riqueza infinita. Se puede expresar conjuntamente: la physis es una potencia generativa aporética, en la medida en que su presencia y su efectivo acto de generación son, al mismo tiempo, su propia despresencia. Siendo presencia despresente y ausencia presente, la physis del mundo finito genera una infinitud intramundana a través de una ontología de lo singular: lo mundano se descubre como una multiplicidad diferencial que, por estar abierta, es inagotable. De ahí que el mundo aparezca como un conjunto de relaciones entre singularidades que necesita ser descifrado sin cese, dado que «en el mundo son las cifras infinitas» ${ }^{64}$. El mundo es abisal y laberíntico; no solo contiene en profundidad un infinito, sino que, además, tal infinitud puede ser aprehendida desde infinitas perspectivas interpretativas. Es por eso por lo que Merleau-Ponty, que caracteriza a todo lo real como physis o ser naciente ${ }^{65}$, observa que el Barroco da concreción peculiar a esta ontología al hacer

este sentido, Gracián sitúa a la persona en una mediación relacional (dialéctica, podríamos decir) entre su pertenencia al mundo y su realización interior, como muestra Helene Andersen (2018).

58. Gracián, Agudeza y Arte de Ingenio, LV, 191-192.

59. García Gibert, 2004, p. 21

60. Gracián, Agudeza y Arte de ingenio, L, p. 736.

61. Gracián, El Criticón, I, crisi 2, p. 823.

62. Un análisis de cómo esta aporía barroca reaparece en posiciones filosóficas actuales se lleva a cabo en Sáez Rueda, 2018.

63. Gracián, El Criticón, I, crisi 6, p. 853.

64. Gracián, El Criticón, III, crisi 4, p. 1152.

65. Por ejemplo, Merleau-Ponty, 1960, p. 240 
del mundo un infinito infinitamente infinito ${ }^{66}$. La sustracción de lo infinito divino como todo absoluto impide comprender el mundo -al modo spinozista- como expresión de una plenitud, de un Dios «absolutamente infinito» que «no implica negación alguna» ${ }^{67}$. Tales rasgos pertenecerían, en el Barroco graciano, al Dios trascendente. En el mundo, la negación de la totalidad divina es, sin embargo, un nihil positivo; es una sustracción operante, gracias a la cual el infinito del mundo queda abierto, él mismo, infinitamente. La ausencia de plenitud, paradójicamente, genera riqueza ilimitada en variabilidad. Solo así se comprende que se pueda hablar de dos infinitos, no solo en Pascal, sino también en Gracián: el microscópico, que es el mundo cifrado, como un libro interminable, y el telescópico, el libro total desde el que virtualmente se mira, porque subyace a todas sus expresiones como la esperanza de un desciframiento que no llega a cumplirse jamás y que acaba en el rotundo silencio ${ }^{68}$.

Lo realmente genético en el mundo es, pues -y a nuestro juicio-, una physis paradójica del mundo finito. Al disiparse «la falsa apariencia de la totalidad»-nos dice Benjamin - el Barroco introduce la «fragilidad de la bella physis» ${ }^{69}$, cuya contradicción interna se refleja en la alegoría barroca. Frente al símbolo, que es un plenum, una totalidad «igual a sí misma» ${ }^{70}$, la alegoría hace estallar en su interior a su propia unificación, de modo que da lugar, por una parte, a un exceso, «la riqueza del derroche», y, por otra, a una simultánea aspiración hacia una totalidad integral inalcanzable, haciendo aparecer, así, a todo lo mundano como ruina «a la espera permanente de un milagro» ${ }^{71}$. Semejante aporética implica una distancia del barroco hispano -interpretado desde Gracián - con el de Leibniz. La multiplicidad diferencial no se reúne en una «armonía preestablecida», como en este último, sino que - como dice Echeverría refiriéndose a Gracián- introduce el «vértigo de la paradoja», insufla en la cosa una ambigüedad (entre su ser ordinario y su ser sobrenatural y extraordinario) con el fin de superarla en una representación que nunca llega a ser tal ${ }^{72}$. En esa operación el imaginario barroco genera una inarmonía, produce un descentramiento, pues la vinculación de lo plural y diferencial está tensada hacia el todo transmundano, de manera excéntrica ${ }^{73}$.

La physis del mundo finito parte de un ápeiron peculiar. Si la potencia generadora es la aporía entre presencia y ausencia de lo divino, tal y como hemos intentado aclarar, el fondo ilimitado e indefinido del que parte es la infinitud infinitamente infinita que tal aporía abre, lo cual se muestra en el carácter descifrador del ingenio. El concepto que el ingenio elabora pretende ser comprehensivo al penetrar en la infinitud del mundo, pues busca, no exactamente las cosas, sino las relaciones

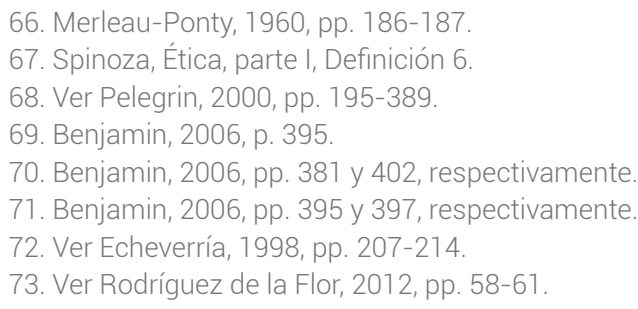


entre las $\operatorname{cosas}^{74}$. Ahora bien, dado que la totalidad ha sido sustraída del mundo, las relaciones conceptuales pueden recomenzar una y otra vez, de acuerdo con la perspectiva que se aplique. Surge así lo que Buci-Glucksmann ha llamado «la locura del ver», un ver desde mil lugares, en multitud de anamorfosis puestas en escena, un ver aporético, pues es simultáneamente, en su envés, un oscuro no-ver: en cada visión está sustraída la vista que cada otra posee ${ }^{75}$. El fondo del que parte la physis es, por tanto, el todo virtual de los desciframientos, de las vinculaciones conceptuales. Virtual, porque ese todo es invocado, anhelado, pero despresente. Tal fondo virtual es abierto, es la infinitud del mundo en el estado no definido e ilimitado de las infinitas posibilidades de desciframiento. Esta virtualidad de la infinitud infinitamente infinita carece de forma concreta. Ahora bien, tal ápeiron se individúa en desciframientos concretos, en conceptos o congregación de conceptos específicamente alumbrados por el ingenio.

\section{CONCLUSIÓN Y REAPERTURA}

Figura esencial del Barroco hispano, contemplado desde la obra de Gracián, es la tensión entre el todo sustraído y la nada del mundo como teatro, vanidad, apariencia. Frente a la hipótesis de que tales categorías se oponen excluyentemente, hemos intentado mostrar que constituyen, más bien, una tensión aporética. La nada del mundo no es su vacío (que el barroco intentaría reespiritualizar), sino la imposibilidad de reunir en un todo omniabarcante la multiplicidad diferencial que se revela en él. Esta sustracción abre un infinito mundanal de relaciones entre singularidades, que son, precisamente, las que intenta reconstruir el concepto, producto del ingenio. La aporía «todo y nada» expresa la simultaneidad entre la presencia del Artífice infinito en lo creado y su despresencia en cuanto unidad orgánica total. Tanto la naturaleza como el mundo humano (cultura) se nos revelan, desde esta perspectiva, como artificios en su sentido genético, es decir, como realidades autopoiéticas cuya forma interna es la de la physis: potencia naturante que emerge desde un fondo informe (ápeiron) y se materializa, individúa o expresa en formas concretas del artificio en su dimensión naturata. Ahora bien, la naturaleza no constituye el fondo estructurante de la cultura, sino su antecedente en el orden de procedencia, estando ambos mediados por el ingenio. La physis natural y la physis del mundo cultural son formas en las que se expresa la englobante physis del mundo finito, una physis aporética y paradójica conformada por la presencia y ausencia simultáneas del todo-infinito divino. Es la potencia de una infinitud infinitamente infinita, por cuanto su ser infinito -inserto en la finitud- es infinitamente reinterpretable en la alegoría y a través de los desciframientos del ingenio. El ascenso a lo eterno, aspiración del homo viator, se desvela, así, simultáneo a una profundización en la infinitud del mundo. 
Es controvertido afirmar, tomando pie en un solo autor, que al Barroco hispano le es inherente, en general, abrir en el mundo finito una profundidad generadora, un abismo como physis. Ampliar así la tesis del presente trabajo implicaría un esfuerzo que desborda sus límites. Queden señalados, al menos -y en forma embrionaria-, otros cauces en forma de hipótesis.

Las acciones de don Quijote son inspiradas por un ideal infinito, en cuanto irrealizable en la finitud. Pero tal infinito aspirado e imposible problematiza las presuntas verdades fácticas del mundo y deja aparecer una realidad intrahistórica, en términos de Unamuno ${ }^{76}$, una «realidad poética», según Ortega y Gasset, en la que es reabsorbido lo ideal-imposible. El infinito ideal, que se revela aporético por su imposibilidad, se descubre en el trasfondo de lo material como «función genérica», es decir, como posibilidad de sus múltiples sentidos, siempre concretos y limitados ${ }^{77}$. Cerezo Galán ve esta caracterización en clave de physis: «Lo poético, en cuanto calificación del acto mismo de la realidad (in genere) hay que entenderlo, a mi juicio, en el sentido etimológico fuerte de poyético (poíesis), esto es, como preñez que precede al alumbramiento de las formas, [...] potencia significativa de la Vida, la única natura naturans, que funda toda cultura y, a la vez, la reabsorbe en sí misma o la juzga y denuncia por su insuficiencia» ${ }^{78}$.

Esta preñez del mundo puede ser rastreada también en el imaginario de Calderón, especialmente en los Autos Sacramentales, en los que es recreada la ausencia de lo eterno divino, insertándola en el mundo en la forma de una ausencia de tiempo, de una eternidad virtual cuya potencia se explicita en sucesos historiados y temporales ${ }^{79}$. Por estas y otras vías cabría mostrar que el Barroco hispano, en general, incorpora la ausencia de lo divino en la facticidad de la existencia finita, en cuya profundidad actúa como una sustracción germinadora, como una physis aporética. Aquí hemos intentado explicitar tan solo este principio a través de la obra de Baltasar Gracián.

\section{BiBLIOgRAFÍA}

Álvarez Solís, Ángel Octavio, La república de la melancolía. Política y subjetividad en el Barroco, Buenos Aires, La Cebra, 2015.

Andersen, Katrine Helene, «Al margen de la filosofía: persona, ingenio y mundo en Baltasar Gracián», Boletín de Estudios Españoles, 95.6, 2018, pp. 587-603.

Ayala, Jorge M., Gracián: vida, estilo y reflexión, Madrid, Cincel, 1987.

Ayala, Jorge M., «lngenio, causa principal de la agudeza y complemento del juicio», Conceptos. Revista de investigación graciana, 1, 2004, pp. 115-132. 
Barroso Fernández, Óscar, «El barroco literario español como vía de solución de los problemas detectados en el giro subjetivo del último Foucault», Pensamiento, 76, 290, 2020, pp. 679-696.

Benjamin, Walter, El origen del Trauerspiel alemán, en Obras Completas, Madrid, Abada, 2006, Libro I, vol. 1, pp. 223-459.

Blüher, Karl, Séneca en España, Madrid, Gredos, 1969.

Borghi, Giuliano, La politica e la tentazione trágica, Milano, Franco Angeli, 1991.

Buci-Glucksmann, Christine, La folie du voir. Une esthétique du virtuel, Paris, Galilée, 2002.

Calvo Martínez, Tomás, «La noción de physis en los orígenes de la filosofía griega», Daímon, 21, 2000, pp. 21-38.

Cerezo Galán, Pedro, El héroe de luto. Ensayos sobre el pensamiento de Baltasar Gracián, Zaragoza, Institución Fernando el Católico, 2015.

Covarrubias Orozco, Sebastián, Tesoro de la lengua castellana o española, Biblioteca Virtual Miguel de Cervantes [1966].

Deleuze, Gilles, El pliegue. Leibniz y el barroco, Barcelona, Paidós, 1989 [1988].

Descartes, René, Principes de la philosophie [1644], Vrin, Bibliothèque des Textes Philosophiques, 2009.

Descartes, René, Reglas para la dirección del espíritu [1623-1629], Madrid, Alianza, 1984.

D'Ors, Eugenio, Lo barroco, Madrid, Alianza, 2002.

Echeverría, Bolívar, La modernidad de lo barroco, México D. F., Era, 1998.

Echeverría, Bolívar, «Meditaciones sobre el barroquismo, I. Alonso Quijano y los indios», en Modernidad y blanquitud, México D. F., Ediciones Era, 2006.

Egido, Aurora, La rosa del silencio. Estudios sobre Gracián, Madrid, Alianza, 1996.

Egido, Aurora, Humanidades y dignidad del hombre en Baltasar Gracián, Salamanca, Ediciones Universidad de Salamanca, 2001.

Egido, Aurora, Bodas de arte e ingenio. Estudios sobre Baltasar Gracián, Barcelona, Acantilado, 2014.

Escribano Cabeza, Miguel, «Baltasar Gracián y los límites de la modernidad filosófica. Una lectura actual de El Criticón», Hipogrifo. Revista de literatura y cultura del Siglo de Oro, 6.2, 2018, pp. 581-620.

Fernández Ramos, José Carlos, «Hobbes y Gracián. El estado de naturaleza en el Leviatán y en El Criticón», Conceptos. Revista de investigación graciana, 7 , 2010, pp. 85-112. 
Fernández Ramos, José Carlos, «Leviathan y la cueva de la nada: Hobbes y Gracián a la luz de sus metáforas», Anuario del Centro de la Universidad Nacional de Educación a Distancia en Calatayud, 23, 2017, pp. 7-15.

García Gibert, Javier, «Artificio, una segunda naturaleza», Conceptos. Revista de investigación graciana, 1, 2004, pp. 13-33.

Gracián, Baltasar, Agudeza y Arte de ingenio [1648], en Obras Completas, ed. Santos Alonso, Madrid, Cátedra, 2011, pp. 433-810.

Gracián, Baltasar, El Criticón [1651, 1653, 1657], en Obras Completas, ed. Santos Alonso, Madrid, Cátedra, 2011, pp. 811-1280.

Gracián, Baltasar, El Discreto [1646], en Obras Completas, ed. Santos Alonso, Madrid, Cátedra, 2011, pp. 271-340.

Gracián, Baltasar, El Héroe [1637], en Obras Completas, ed. Santos Alonso, Madrid, Cátedra, 2011, pp. 71-140.

Gracián, Baltasar, Obras Completas, ed. Santos Alonso, Madrid, Cátedra, 2011.

Gracián, Baltasar, Oráculo manual y Arte de prudencia [1647], en Obras Completas, ed. Santos Alonso, Madrid, Cátedra, 2011, pp. 341-432.

Goldmann, Lucien, Le dieu caché, Paris, Gallimard, 1955.

González de Requena Farré, Juan Antonio, «Proyecciones del Arte de prudencia de Gracián en el Homo Politicus moderno», Open Insight, 10.19, 2019, pp. 99-127.

Hauser, Arnold, The Social History of Art, Londres, Routledge / Kedan Paul, 1951.

Hidalgo Serna, Emilio, El pensamiento ingenioso en Baltasar Gracián. El concepto y su función lógica, Barcelona, Anthropos, 1993.

Higuera Espín, Javier de la, «Lo insoportable de la verdad», en El mundo de Baltasar Gracián, ed. Juan Francisco García Casanova, Granada, Universidad de Granada, 2002, pp. 303-342.

Jankélévitch, Vladimir, «Apariencia y manera», Cuaderno Gris, Época II, 5, 1992, pp. 76-87.

Leibniz, Gottfried Wilhelm, Monadología [1714], Madrid, Biblioteca Nueva, 2001.

Leibniz, Gottfried Wilhelm, Die Philosophischen Schriften, ed. Karl Immanuel Gerhardt, Hildesheilm, Olms, 1965.

Maravall, José Antonio, La cultura del Barroco, Madrid, Ariel, 1990.

Merleau-Ponty, Maurice, Signes, Paris, Gallimard, 1960.

Orio de Miguel, Bernardino, «Algunos aspectos no cartesianos del racionalismo de Spinoza y de Leibniz. Sobre la naturaleza de los cuerpos», Enrahonar, 59, 2017, pp. 71-90

Ortega y Gasset, José, Meditaciones del «Quijote», en Obras Completas, ed. Fundación Ortega y Gasset, Madrid, Taurus, 2017, tomo I, pp. 747-828. 
Pelegrin, Benito, Figurations de l'infini. L'âge baroque européen, Paris, Seuil, 2000.

Río Parra, Elena del, «El auto sacramental calderoniano como tránsito del no-tiempo al tiempo virtual», Anuario Calderoniano, 5, 2012, pp. 131-144.

Rodríguez de la Flor, Fernando, Pasiones frías. Secreto y disimulación en el barroco hispano, Madrid, Marcial Pons, 2005.

Rodríguez de la Flor, Fernando, Mundo simbólico. Poética, política y teurgia en el barroco hispano, Madrid, Akal, 2012.

Rosset, Clément, La antinaturaleza, Madrid, Taurus, 1974.

Sáez Rueda, Luis, El ocaso de Occidente, Barcelona, Herder, 2015.

Sáez Rueda, Luis, «Del Cosmos al Caosmos en la reapropiación actual del Barroco. Una nueva normatividad para afrontar la crisis epocal», Anales del Seminario de Historia de la Filosofía, 35.1, 2018, pp. 51-75.

Simondon, Gilbert, La individuación a la luz de las nociones de forma e información, Buenos Aires, La Cebra / Cactus, 2009 [1958].

Spinoza, Baruch, Ética demostrada según el orden geométrico [1677], Madrid, Editora Nacional, 1984.

Trías, Eugenio, «Escenificación del infinito (interpretación del Barroco)», en Lo bello y lo siniestro, Barcelona, Ariel, 1996.

Unamuno, Miguel de, «El Caballero de la Triste Figura. Ensayo iconológico», en Obras Completas, ed. Ricardo Senabre, Madrid, Biblioteca Castro, 2007, VIII, pp. 257-277. 